\title{
A AUTORIA NEGRO-FEMININA NO BRASIL E EM MOÇAMBIQUE: O ESCREVER ENTRE DOBRAS E INSURGÊNCIAS
}

\author{
Ana Rita Santiago
}

\begin{abstract}
Resumo: A produção literária de escritoras negras no Brasil e africanas de Moçambique tem sido marcada por um árduo exercício de dessilenciamento de suas vozes autorais e visibilização de suas tessituras literárias. Diante disso, este artigo objetiva refletir sobre modos de (re) existências das autoras desses países. Propõe-se ainda discutir como em suas escritas elas (re) criam possibilidades de sentidos de vida, contrapondo-se às narratividades, demarcações, geografias e práticas que lhes fixam em "lugares" de subjugações e interdições. Apresentam-se, neste texto, leituras descritivo-interpretativas de algumas de suas dicções literárias para compreensão de como elas forjam os significados e dobras de (re) existir, criar mundos, caminhos e resistência.
\end{abstract}

Palavras-Chave: Autoria negro-feminina. (Re) Existência. Literatura.

\begin{abstract}
The literary production of black women writers in Brazil and africans of Mozambique has been marked by an arduous exercise of desilencing their authorial voices and making their literary texts more visible. Given this, the paper reflect on ways of (re) existences of theses authors. It is also proposed to discuss how in their writings they (re) create possibilities of meanings to life, in contrast to the narratives, demarcations, geographies and practices that fix them in "places" of subjugation and interdictions. It is expected with this text descriptive-interpretative readings of some of his literary diction to understand how they forge the meanings and folds of (re) exist, create worlds, and ways of resistance.
\end{abstract}

Keywords: Black-female authorship. (Re) Existence. Literature.

\section{Algumas Palavras Iniciais}

O poeta e o mundo

Pois, sim

O mundo cabe dentro do poema.

No insólito da imagem e da letra quebra-se a fronteira do que existe e do que não tem fim.

Mas, no fim do ponto e vírgula, o mundo sai pela mão do poeta da paixão pela procura do verso. 


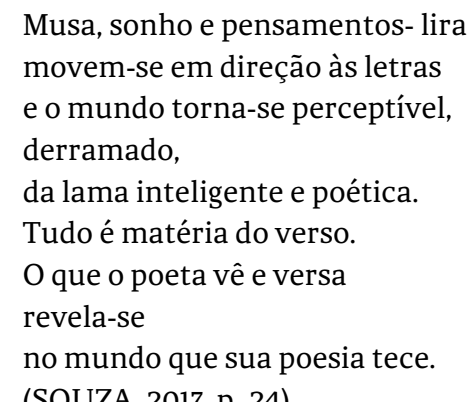

Este texto advém de um mapeamento elaborado sobre autoras moçambicanas, entre 2015 e 2017², apresentado no livro Cartografias em Construção - Algumas Escritoras Moçambicanas (EDUFRB, 2019), e de estudos e pesquisas realizados, no âmbito do doutoramento, sobre autoria feminina negra na Bahia, dos quais derivou o livro Vozes Literárias de Escritoras Negras (EDUFB, 2010). A produção literária de mulheres negras brasileiras e moçambicanas tem desenhado, por vezes, dobras e trânsitos de uma dicção literária atravessada por temas e propósitos que se circunscrevem entre tradições, memórias, identidades e histórias e também, a vida cotidiana e o mundo, como canta a voz poética de $O$ poeta e o mundo, de Jovina Souza, sonhos por transformações, vivências e reinvenções de (re) existências. Neste sentido, este texto aponta as suas tessituras literárias como práticas discursivas que circulam entre os seus devires, marcados pela constituição da autoria, protoganismos, resistências, empoderamento, as travessias e pontes hodiernas do (re) existir.

A elaboração de cartografias literárias produzida por mulheres negras no Brasil em Moçambique não tem sido uma tarefa fácil e sem complexidades aos (às) estudiosos (as) de literaturas daqui e de lá, visto que a 'naturalização' do gênero dos poetas e romancistas, hegemônica e tradicionalmente, tem uma historiografia, prevalentemente, de predominância masculina, imperando, também nas Letras, a soberania

${ }^{1}$ Este texto deriva da pesquisa "A Literatura de Autoria Afro-feminina em Moçambique e na BahiaBrasil”, desenvolvida no âmbito de estágio pós-doutoral (2016-2017), realizado na Université Paris Descartes - Paris V - Sorbonne, França, e supervisionado pelo Prof. Michel Maffesoli e pela Profa. Ana Maria Peçanha. Essa investigação integra a pesquisa, em andamento, "A Literatura Afro-feminina em Trânsito: África Portuguesa e Bahia - Brasil” (2015-2020), vinculado ao Grupo de Pesquisa "Linguagens, Literaturas e Diversidades" (CNPQ-UFRB). 
patriarcal. Ainda assim, elas têm cumprido, como um devir-resistência, um árduo labor de (des) silenciar as suas vozes autorais e, a um só tempo, forjar, como se desenha neste texto, suas produções literárias.

As suas tessituras não se configuram por sobreposição àquela elaborada pelos homens. Tampouco são compreendidas, por seu estilo, conteúdo e forma, como expressões de uma suposta natureza ou subjetividade feminino-negra por serem escritas por mulheres negras daqui e de Moçambique. As suas temáticas, narratividades, vozes, discursividades e representações são, pois, definidoras de suas escrituras, as quais são tensionadas, sobretudo por escritoras negras brasileiras, pelas vivências socioculturais e as relações de gênero e etnicorraciais, entrecruzadas pelo desejo de palavras literárias emancipatórias e tatuadas por memórias e histórias de si (nós).

A literatura dessas autoras tem, portanto, o intuito, dentre outros, de criar discursos poéticos e narrativos que ficcionalizem suas histórias e memórias, os seus sonhos e realizações e também, por vezes, predominantemente, no Brasil, os conflitos, sofrimentos e resistências resultantes das experiências de racismo e sexismo, por elas vividas ou presenciadas. Com as suas sintaxes literárias, elas, inclusive, tecem versos e prosas em que se negociem identidades, valorizam, mobilizam e ou tensionam histórias, ancestralidades e repertórios culturais afro-brasileiros e moçambicanos.

Além disso, compreendendo a literatura como uma possibilidade de fortalecer a potência da vida, elas inventam narrativas e poemas que entoem cantos às vicissitudes da existência, tais como o nascimento, a vida, a morte $\mathrm{e}$ os sentimentos, sensações e inerências associados ao existir - alegrias, dores, (des) amores, (des) ilusões, dissabores, ciúmes, tristezas, esperança etc. -. Para tanto, elas buscam garantir estratégias de escrita, publicações e divulgação de suas produções literárias, a fim de romper com o esquecimento e não autorização a que, historicamente, se submetem suas vozes e autoria. 


\title{
Autoria Negro-feminina Aqui e Lá
}

\author{
Súplica \\ Tirem-nos tudo, \\ mas deixem-nos a música! \\ Tirem-nos a terra em que nascemos, \\ onde crescemos \\ e onde descobrimos pela primeira vez \\ que o mundo é assim: \\ um tabuleiro de xadrez... \\ Tirem-nos a luz do sol que nos aquece, \\ a lua lírica do shingombela \\ nas noites mulatas \\ da selva moçambicana \\ (essa lua que nos semeou no coração \\ a poesia que encontramos na vida) \\ tirem-nos a palhota - a humilde cubata \\ onde vivemos e amamos, \\ tirem-nos a machamba que nos dá o pão, \\ tirem-nos o calor do lume \\ (que nos é quase tudo) \\ - mas não nos tirem a música! \\ Podem desterrar-nos, \\ levar-nos \\ para longe terras, \\ vender-nos como mercadoria, \\ acorrentar-nos \\ à terra, do sol à lua e da lua ao sol, \\ mas seremos sempre livres \\ se nos deixarem a música! \\ Que onde estiver nossa canção \\ mesmo escravos, senhores seremos; \\ e mesmo mortos, viveremos, \\ e no nosso lamento escravo \\ estará a terra onde nascemos, \\ a luz do nosso sol, \\ a lua dos shingombelas, \\ o calor do lume, \\ a palhota onde vivemos, \\ a machamba que nos dá o pão!
}


E tudo será novamente nosso, ainda que cadeias nos pés e azorrague no dorso... E o nosso queixume será uma libertação derramada em nosso canto!

- Por isso pedimos, de joelhos pedimos: Tirem-nos tudo... mas não nos tirem a vida, não nos levem a música! (4.01.1949) (SOUSA, 2011, p. 25-26).

Na Ilha de Moçambique, das águas turvas e cinzas, mas também cristalinas e límpidas, ainda que a poeta Noémia Sousa seja considerada a mãe dos poetas moçambicanos, prepondera, no país, a referência de identidade autoral masculina. São os homens que mais escrevem, publicam e usufruem mais notoriedade. A invisibilidade de nomes de escritoras em Moçambique e a pouca valorização de suas construções literárias, por vezes, consideradas de pouco valor estético, favorece o silenciamento de suas vozes autorais e o cerceamento de sua escrita literária. Lá, também, ecoam e emergem os célebres questionamentos quando a autoria feminina é um dos desassossegos investigativos: As mulheres escrevem? ao invés de Que mulheres escrevem? O quê, por que e como escrevem? Como publicam e circulam suas obras?.

No país, circulam quase 30 línguas em seus distritos e províncias. Em contrapartida, a língua portuguesa é o único idioma oficial e menos de $60 \%$ da população tem o domínio dessa língua. A ausência de políticas públicas em favor dos Direitos Culturais e do Patrimônio Cultural; a falta de bibliotecas, de planos, programas e ações institucionais de acesso ao livro e de incentivo à leitura e à escrita; a não democratização dos bens culturais e da educação; a inexistência de políticas editoriais; o nível baixo de escolaridade, predominante entre as mulheres, dentre outros elementos, associados às desigualdades de gênero, fortalecem o recrudescimento do empoderamento das mulheres, bem como promovem o apagamento da identidade autoral feminina em Moçambique, igualmente, em outras águas do Índico e do 
Atlântico. Não obstante essa realidade há inúmeras iniciativas em favor da leitura e da literatura no país, tais como prêmios, clubes e círculos de leituras, projetos de formação de leitores(as) e de promoção do livro e, por conseguinte, da literatura.

Mulheres moçambicanas, principalmente, as mais jovens, participam de coletivos de gênero e de arte, escrevem, mesmo que nem todas participam, satisfatoriamente, de circuitos e projetos artístico-culturais e literários do país. As autoras em Moçambique têm construído, no e a caminho, múltiplos percursos editoriais, nacional e, internacionalmente, algumas. Ainda não de modo equânime, desejável e necessário, várias já conseguem publicar e, de modo criativo e resistente, formar público leitor nacional e algumas (poucas ainda) até internacionalmente.

É preciso compreender a produção literária contemporânea dessas autoras africanas como um projeto integrante da literatura moçambicana, através do qual se gestam palavras e narrativas (en) cantadas, comprometidas, com a fruição e defesa da poesis, da arte, como consta no poema Súplica, de Noémia de Sousa, mas também com modos criativos e discursivos de (re) invenções e mobilizações de existências, de pensamentos, culturas e identidades.

Ao visitarmos as suas escritas constatamos que seus passos vêm de longe! Noémia de Sousa, Lina Magaia, Josima Machel, Fátima Langa, dentre outras, fizeram suas travessias literárias em prol da libertação do jugo da dominação colonial portuguesa e da formação da nação, além de forjarem pontes, também literárias, valorizando paisagens, cores, cheiros, narrativas, cosmogonias, repertórios culturais e histórias locais.

Lília Momplé, Paulina Chiziane, Isabel Ferrão, Felismina Velho, Sónia Sultuane, Tánia Tomé, Cri Essencia, Rosa Langa, Sara Rosário, Lica Sebastião, Lídia Mussa, Isabel Ferrão, Isabel Gil, Nilzete Monteiro, Npaiy, Énia Wa Ka Lipanga, Rosa Isabel Maiòpué, Henriqueta Macuácua, Vigília Ferrão, Emma Xyx, Hirodina Joshua, Dama do Bling, Donia Tembe, Emília Alexandre, Eunice Matavele, Amilca Ismael, Carla Soeiro, Clarisse Machanguana, Cláudia Constance Leal, Melita Matsinhe, Celina Sheila Macome, Hirondina Joshua, dentre outras, inscrevem as suas identidades autorais, em construção, a trilhar caminhos, desenhando atravessamentos e criando pontes e dobras 
para um pulsante crescimento e fortalecimento da dicção literária de mulheres em Moçambique.

As trilhas literárias de mulheres negras, no Brasil, também se assemelham àquelas descritas referentes às autoras africanas de Moçambique. O silenciamento, a invisibilidade e o apagamento de suas vozes literárias compõem o seu percurso autoral. Ainda assim, os seus textos têm se configurado como uma gramática literária atravessada por temas que desfilam entre anseios por transformações e ressignificações de (re) existências $^{2}$ e por fios históricos, imaginários e existenciais que tecem, descontínua e paulatinamente.

Em suas escrituras, elas inventam vozes, modos e motivos de existir e permanecer vivas. Com figuras e universos diferenciadores, quiçá, transgressores, como potências de vida e longe da esfera das representações, marcadas por atributos relacionados à escravização e papéis sociais de subalternidade, exotismo, libido exacerbado, elas criam possibilidades de sentidos de (re) existir e de resistir, entrecruzados pelo Eu e Nós, contrapondose, como se apresenta a voz de enunciação de Oin, de Mel Adún, às discursividades, demarcações, geografias e práticas que lhes fixam em "lugares" de subjugações, controles e interdições.

Oin

Não se iludam com a doçura do meu nome;

Sou oxé bilaminado

Alcançando a garganta dos que lutam pra manter o status quo.

O contorno do agadá de meu guerreiro. A seta certeira do arqueiro.

Nos dias de ouro renasço redonda. Dourada.

Sou peixe pequeno beliscando a barra da saia correnteza. Nesses dias... adoço-me.

(ADÙN, 2014, p. 15).

Longe de lugares tempos e estados sólidos e estáveis, entre os múltiplos ditos e desditos que forjam, em seus percursos, elas também ousam

${ }^{2}$ O sentido de (re) existência (SANTIAGO, 2018), aqui atribuído, é relacionado ao assenhoramento da escrita por autoras negras como modos de reinvenções de existências. 
apropriar-se da arte da palavra para escrever de si (nós) como oportunidade para (des) dizer, pela linguagem poética, ditos sobre si, bem como modos de (re) existir, logo de instituir-se. É um exercício autoral que pode, inclusive, operacionalizar discursos tidos como verdadeiros ou hegemônicos em probabilidades de reversões de olhares e recriações de si e reinvenções de outras, deslocando-se do território de personagens para autoras. Tal movimento, indubitavelmente, metamorfoseia, não só o transcurso de suas vidas, mas também das trilhas literárias e de suas auto-narrativas.

Ao visitarmos as obras literárias de autoras negras brasileiras, tais como de Maria Firmina do Reis, Auta de Souza, Antonieta de Barros, Carolina Maria de Jesus, Gilka Machado, Beatriz Nascimento, Nivalda Costa, Aline França, Geni Guimarães, Miriam Alves, Cristiane Sobral, Elizandra Souza, Mel Adún, Rita Santana, Lívia Natália, Jocélia Fonseca, Ana Maria Gonçalves, Conceição Evaristo, Alzira Rufino, Lia Vieira, Mel Duarte, Jarid Arraes, Lubi Prates, Ana Fátima Cruz dos Santos, Joelma Santos, Vânia Melo, Louise Queiroz, Eliane Alves Cruz, Jovina Souza, Louise Queiroz, Hildalia Cordeiro, Vânia Melo, Gonesa Gonçalves, Lidiane Ferreira, dentre outras, denotamos o quão ainda é importante apontar o cerceamento de vozes autorais de mulheres negras, bem como as práticas de invisibilidade de suas escrituras em circuitos culturais e literários. Torna-se mais relevante ainda compreender as suas sintaxes literárias como potências de vida e um devir-resistência, ao reverter e mobilizar as significações hegemônicas de si (nós) e, concomitantemente, forjar as narratividades de construção de outras (re) existências e figurar sentidos e dobras de se estar e inventar mundos, caminhos e existências e resistências.

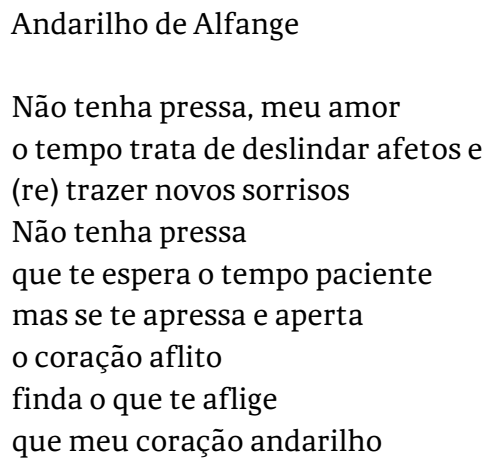


procurará outros caminhos.

(GONÇALVES, 2016, p. 62).

As dicções literárias dessas escritoras, pois, apresentam-se comprometidas com mobilizações que promovam outros caminhos e modos de viver, como canta o sujeito poético de Andarilho de Alfange, de Gonesa Gonçalves. É preciso viver! Insurgentes e, às vezes, aquilombadas em coletivos, elas giram as suas assinaturas e sintaxes poéticas em construção. Inventam-se poetas para (des) dizer de si (nós) e desdizem, poetizar as suas existências, os seus corpos e inventar lirismos em que se cantam e narram-se (nós).

Assenhoradas da palavra, autoras, daqui e de lá, apropriam-se do vivido ou imaginado, tornando-os inefáveis e ficcionalizados, provocando, ora fruição ora desassossegos, poéticos de existências e resistências. Elas também inscrevem e (re) escrevem, em seus versos, recordações e lembranças esparsas e aleatórias, inventando memórias, igualmente, anacrônicas, pessoais e coletivas, esgarçando e diluindo fronteiras entre os eu (s) autoral, real e o ficcional. Conhecer as suas escrituras, nesse ínterim, significa reconhecê-las como palavras de aquilombamentos e ressignificações imaginárias e ficcionais, do vivido e do porvir, individual e coletivo, de ancestralidades, histórias, caminhos, sonhos, desejos, mas também desamores, angústias, dores, sofrimentos, advindos de suas insistências e persistências, do ato de existir e desmobilizar supostas verdades e fixidez do seu viver.

\section{O Devir-resistência: Escrever para (Re) Existir}

Parte da história

Olho e não vejo a distância

E o alcance de parte da história

Dia a dia como a gota d'água

Experimento uma nova memória.

(XYX, 2015, p. 26).

Pontos de Interrogaçầo, v. 10, n. 2, Ediçầo Especial, jul.-dez., p. 121-134, 2020. 
O devir-resistência, sob a esteira do conceito de resistência ${ }^{3}$, atribuído por M. Foucault (1998) e do devir-revolucionário ${ }^{4}$, desenhado por Deleuze (1990), constitui-se como possíveis formas de forjar novos modos de luta e de se fazer historias e memórias, como a voz lírica de Parte da história, da escritora moçambicana Emmy Xyx, intervenções e mobilizações através do discurso criativo e outros modos de fazer política, tendo em vista ações libertárias no (do) presente. É uma prática existencial do presente que se reverbera em atitudes revolucionárias e libertárias que operam no aqui-eagora e em experiências que buscam relações horizontais.

Em palavras literárias de algumas autoras negras, no Brasil e em África, passeiam exercícios de reinvenções e existências, em que se constroem outros modos de poetizar o existir e se aproximam dos propósitos do devir-resistência. Os corpos negros, por exemplo, são travestidos por imagens, desejos, movimentos pulsantes, imbuídos de significados, sensações e sentimentos, como mostra a voz ousada, autônoma e emancipada de Embate de víboras, de Rita Santana.

\author{
Embate de víboras \\ O meu corpo toma o teu, \\ E te alinhava na minha pele. \\ Fere velhas feridas tuas \\ E não mais regressa, \\ Deixando ao relento o teu ciúme. \\ O teu corpo vinha de sangue \\ O esmalte dos meus dentes. \\ Morde a mação e diz malsã \\ Minha sandice de anemias \\ Eu e Tu: \\ Adultério, torpezas e vilanias. \\ (SANTANA, 2016, p. 49).
}

\footnotetext{
${ }^{3}$ Os sentidos atribuídos à resistência transitam como formas de poder (FOUCAULT, 1997) entre o combate e o enfrentamento, individuais e coletivos, de dominações, racismo, sexismo e intolerâncias.

${ }^{4}$ O sentido de devir-revolucionário, apresentado por G. Deleuze (1990), refere-se às possibilidades de se construir práticas de enfrentamento de intolerâncias e respostas para expurgar a vergonha das atrocidades derivadas dos regimes fascistas e nazistas, viabilizando estratégias de se (re) ocupar e acreditar no mundo e em transformações, não mais, tão somente, pela esfera da macropolítica e da tomada do poder, mas também pelas revoluções cotidianas, notabilizadas por meio de atos militantes e de rebeldia no hodierno (micropoder).
} 
Com sinais diferenciadores e transgressores daqueles que transitam em tradições literárias e se apresentam, por vezes, como corpo-memória, corpo-movimento, corpo-ancestral, dentre outros, como a voz narradora do conto Maudlane - O criador, da contista e romancista Paulina Chiziane.

Minha avó. Minha mãe - diz Chivambo - duas pedras basilares no edifício da vida. O que seria de mim sem a vossa existência? Venci, alicerçado no poder das vossas almas. São vossas todas as vitórias deste mundo. É vossa toda a grandeza que brilhará nas cores da nossa bandeira, Amaldiçoado seja quem louvar os meus atos sem invocar os vossos feitos (CHIZIANE, 2013, p. 86).

Assim, como práticas discursivas de (re) invenção, elas, por vezes, tatuam, em vozes poéticas, traços diferenciadores, através dos quais esses corpos são inventados (in) dóceis, dissidentes e como construções socioculturais e ancestrais, tal como entoa a voz poética de Desnuda, de Jocelia Fonseca.

Desnuda

Ficarei nua

Perante o espelho

E dançarei linda

Diante dos meus próprios olhos.

Nessa ginga que me permite o reggae

Meu corpo se embala

E me dá esse sentido

Sou parte de uma tribo

De peixe nadando como quem flutua.

Sou parte de uma tribo

Dizimada com a exploração branqueadora

Mas...

Entre peixes, reggaes e sonhos

Me aprofundo em mim mesma

Sou forte, bela e insubmissa...

(FONSECA, 2012, p. 73). 
Como poéticas de resistência no (do) cotidiano, a sua escrita literária tem inventado e valorizado ações cotidianas como sinalização de posicionamentos políticos de resistência. Tal poética de (re) existências e do cotidiano se apresenta como possibilidades inventivas de estar no mundo e também de fazer política, como apela a voz do pequeno poema Tambor, de Melita Matsinhe.

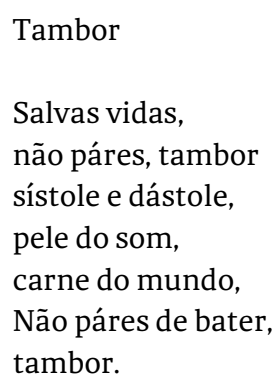

(MATSINHE, 2017, p. 59).

Como ato de micropoder, o devir-resistência de autoras negras, no Brasil e em Moçambique, é, por vezes, motivação e razão para as suas dobras literárias. A arte da escrita, como prática do devir-resistência, torna-se uma saída para não só dizer de si (nós), mas também para reinventar modos de (re) existir e forjar alternativas de seguir e estar no mundo. As singularidades, juntamente com o potencial criativo, que desfilam em suas poéticas e narrativas, associadas a uma multiplicidade de motes, temas, situações, inquietações e vivências, como mulheres negras, impulsionam, por conseguinte, uma escrita pulsante, movimentada por um agir micropolítico, mobilizando inovações e resistências que desembocam do eu-para-si para outros (as).

\section{Algumas Considerações (In) Conclusivas}

Tessituras literárias de mulheres negras, do Brasil e de Moçambique, apresentam-se como escritas para (re) existir, tornando-se chaves promissoras e contra-hegemônicas de autoconhecimento e (re) invenção de si (nós) e de mundos. Neste sentido, elas poderão, indubitavelmente, colaborar, 
como expressão do devir-resistência, com o tensionamento e a ressignificação de culturas africanas e negro-brasileiras.

A autoria negro-feminina no Brasil e em Áfricas é um dos temas que se apresentam como uma potência de vida mediante os tempos e as complexidades da existência de negros(as) brasileiros(as), de populações africanas em Áfricas e nas diásporas. Talvez nisso consista alguma pertinência deste texto e a sua indicação de que essa reflexão precisa ser fortalecida e continuada. Possivelmente, esse é (e será) um dos caminhos, para que possamos forjar outras trilhas e dobras possíveis e satisfatórias de divulgação de suas insurgentes palavras literárias.

\section{Referências}

ADÚN, Mel. Oin. In: ADÚN, Gellwaar; ADÚN, Mel; RATTS, Alex (Org.). Ogum's Toques Negros - Coletânea Poética. Salvador: Editora Ogum's Toques Negros, 2014.

DELEUZE, G.; NEGRI, Toni. O devir revolucionário e as criações políticas. Entrevista de Gilles Deleuze e Toni Negri. Trad. João H. Costa Vargas. Novos Estudos CEBRAP. N. 28, outubro 1990. p. 67-73.

CHIZIANE, Paulina. Maudlane - O criador. In: As Andorinhas. Belo Horizonte: Nadyala, 2013.

FONSECA, Jocelia. Desnuda. In: BARBOSA, Cléa; FONSECA, Jocelia; OLIVEIRA, Lutigarde. Importuno Poético. Salvador: Ed. Revoluo, 2012.

FOUCAUlT, M. A Microfísica do Poder. Trad. Andréa Daher. Rio de Janeiro: Jorge Zahar, 1997.

GONÇALVES, Gonesa. Andarilho de Alfange. In: Átomo Pseudopoeta, Cezar Sobrino, Cristiane Sobrinho, Davi Nunes, David Alves, et ali. Enegrescência. Salvador: Editora Ogum's Toques Negros, 2016.

MATSINHE, Melita. TamboR. In: Ignição dos Sonhos. Maputo: Fundação Fernando Leite Couto, 2017.

SANTANA, Rita. Embate de víboras. In: Alforrias. Ilhéus-BA: Editus, 2016.

SANTIAGO, Ana Rita. (Re) Existências e o Devir Revolucionário na Literatura Negro-feminina. Fólio - Revista de Letras. Vitória da Conquista-BA, Vol. 10, n. 2, jul-dez, 2018, p. 11-33. 
SOUSA, Noémia. Súplica. In: Sangue Negro-Poesia. Maputo: Marimbique, 2011.

SOUZA, Jovina. O Poeta e o Mundo. In: O caminho das Estações. Itabuna-BA: Mondrongo, 2018.

YXY, Emmy. Parte da história. In: Escritas na Mão do Mar à Ria. Maputo: Ciedima, Lda, 2015.

Recebido em 20 de novembro de 2020

Aceito em 15 de dezembro de 2020 